\title{
Initial Validation of the Support Mobilization for Work Stressors Inventory
}

\begin{abstract}
Although there has been significant research into coping with work stress, support mobilization has been largely overlooked. When workplace stressors adversely influence employees, they often turn to colleagues and supervisors for feedback and support. This article outlines the development of a new multidimensional measure of support mobilization: The Support Mobilization for Work Stressors (SMWS) inventory. Two studies revealed that the SMWS inventory shows evidence of reliability, factor structure dimensionality and replication across samples, convergent and discriminant validity with a perceived available support measure, and criterion-related validity with organizational outcomes. The 12 -item inventory is rated with reference to 3 sources of support (supervisor, colleagues, non-work people), and assesses how often an employee has approached each of those sources to obtain four supportive functions (emotional, informational, instrumental, appraisal); thus producing 12 distinct support mobilization constructs.

Words: 137
\end{abstract}

Keywords: social support, coping, work stressors, scale development, structural equation modeling 


\section{Initial Validation of the Support Mobilization for Work Stressors Inventory}

\section{Introduction}

Interpersonal conflict, work overload, technological changes, restructuring and downsizing are just some of the workplace stressors employees increasingly face in the globalization-sensitive new millennium (Winefield, 2002). For the majority of workers, with the presence of workplace stressors comes the experience of stress and potentially, reductions in mental health, job satisfaction and productivity (see Lawrence and Callan, 2011; Sutherland and Cooper, 2000). In their highly influential stress and coping theory, Lazarus and Folkman (1984) argue that once a situation is appraised as stressful, an individual activates a coping response with the aim of reducing their experience of stress. Enacting functional coping responses alleviate the negative effects of stress on both short-term (e.g., state affect, physiological states) and long-term outcomes (e.g., job satisfaction, turnover intentions, psychological well-being; Lazarus and Folkman, 1984; Masel, Terry, and Gribble, 1996).

Coping in organizations has been a widely researched area and there is a clear link between functional coping and the ability of the individual to alleviate the longer-term negative consequences of stress (Lazarus and Folkman, 1984, Skinner, Edge, Altman and Sherwood, 2003). Coping responses range from intrapersonal 'problem-focused' strategies such as planned problem-solving, intrapersonal 'emotion-focused' strategies such as wishful thinking, to interpersonal behaviors such as support mobilization. The latter is defined as a process of active seeking, obtaining and utilizing support from others in response to stress (Lazarus and Folkman, 1984; Folkman and Lazarus, 1985; Skinner et al., 2003).

Although employees' use of intrapersonal coping strategies has been extensively researched (see Dewe, Cox, and Ferguson, 1996; Masel et al., 1996) and the conceptualization and operationalization of these strategies have been thoroughly critiqued (e.g., Guppy et al., 
2004; Skinner et al., 2003), little attention has been paid to support mobilization coping conceptually, operationally or empirically. Nor have researchers conceptually and empirically considered the influence of mobilizing different supportive functions (e.g., emotional) from different sources of support (e.g., colleagues; see Carver, Scheier, and Weintraub, 1989; Wills and Shinar, 2000).

The lack of attention paid to support mobilization is quite surprising given researchers' focus on the associated concept of social support. Social support, whether in the guise of social integration, social network structure, or relational support concepts such as perceived support availability or received support, has been extensively researched and critiqued (Anderson, 2008; Cohen and Wills, 1985; Lawrence, Gardner, and Callan, 2007; Schwarzer and Leppin, 1991). Our aim in this article is to fill a gap in the literature in relation to workplace support mobilization by developing a work-applicable multi-dimensional conceptualization and operationalized measure of support mobilization.

In this article, and in line with stress and coping theory (e.g., Lazarus and Folkman, 1984, p. 327), we conceptualize support mobilization, at a basic level, as the overt seeking, obtaining and utilizing of helpful support from others in response to situational work stress. In line with the social support literature (House, 1981; Terry, Rawle, and Callan, 1995), we further contend that the 'support' employees mobilize consists of different supportive functions (e.g., emotional, informational, instrumental, appraisal) from different sources of support (e.g., supervisors, colleagues, and external, non-work people). We note that the mobilization term is often used interchangeably with support seeking, but we specifically focus on mobilization as a label for the construct. This label more accurately encompasses the theorized interpersonal behavioral process enacted to cope with stress and this is reflected in the scale we have developed. We do not suggest that our scale will assess issues like the 
quality, satisfaction, or reciprocity of that support (Schwarzer and Leppin, 1991), as this is outside the scope of our research.

The aim of our research is to fill a gap in the literature in relation to workplace support mobilization by developing a work-applicable multi-dimensional conceptualization and operationalized measure of support mobilization. We note that comprehensive measures of perceived available support exist (e.g., Lawrence et al., 2007). However, in our research we are focusing on the mobilization of support, that is, we are not focusing on what support is theoretically available, but rather the actual support that is mobilized. We argue that our conceptualization underlying this new measure has the advantage of bringing the coping strategy literature in line with the social support literature to focus more explicitly on the mobilization of distinct supportive functions from distinct sources.

Organizations are increasingly being structured around interdependent work teams (Salas, Cooke, and Rosen, 2008). When problems such as workload changes or interpersonal conflicts arise, employees will often need to mobilize support from their colleagues (Zellars and Perrewe, 2001). New employees additionally look to colleagues for advice and feedback about their work roles and to understand workplace social norms (Morrison, 1993).

Alternatively, employees primarily seek official organizational support by approaching their frontline supervisors (Callan and Lawrence, 2009). Some employees who may feel vulnerable at work might look to other sources for support, such as non-work friends and family (Lawrence, 2006). We argue that our new measure will allow for a deeper insight into the circumstances under which specific supportive interactions are mobilized in response to different workplace stressors.

Moreover, we argue that the new multi-dimensional inventory can be a valuable tool when HR managers are planning and evaluating targeted workplace interventions. HR managers in organizations typically implement a range of organizational (work- and interface- 
directed) stress management programs to improve the support structures that will enable employees to cope more effectively with new employment and ongoing organizational changes (Wall and Wood, 2005). Information obtained from the new measure, for example, will allow HR managers to gauge from employees' mobilization behaviors the success (or otherwise) of their efforts to train supportive supervisors and develop supportive climates and positive socialization initiatives within organizational units and work teams.

In this article, we first develop a framework of work-related support mobilization that reflects the multidimensional nature of the concept and position it within stress and coping theory. Next, based on the newly developed framework, and an examination of existing scales, a multidimensional operationalized scale of support mobilization is developed that examines support mobilization coping behaviors in organizational settings. This scale measures both function and source of support mobilization for the specific context of work related problems. Finally, after development of the new inventory, we show evidence of the

construct validity (factor structure dimensionality, factor structure replication, convergent and discriminant validity) and criterion-related validity of the new measure through a series of analyses conducted on data from two studies.

\subsection{Framework for understanding support mobilization}

The existing literature has many examples of the inconsistent conceptualization of support mobilization (see reviews by Schwarzer and Leppin, 1991; Skinner et al., 2003). Generally, support mobilization is one form of behavioral social support that is activated in order to deal with specific stressful situations (Schwarzer and Leppin, 1991). Support mobilization, as an active process resulting in specific behaviors, is distinguishable from other concepts such as perceived available support. The latter is perceptual in nature and explains the degree to which individuals perceive that they can rely on others for support (Edwards, Webster, Van Laar, and Easton, 2008; Lawrence et al., 2007; Schwarzer and Leppin, 1991). 
Eckenrode and Wethington (1990) propose that support mobilization can be both unsolicited or overtly solicited by an individual. Others such as Cutrona, Suhr and MacFarlane (1990) argue for a more finely grained distinction which identifies a broad range of differing support seeking behaviors from direct complaint, to expressing doubt, and indirectly, via nonverbal emotional displays. It is the overt help-seeking component of support mobilization that has been the major focus in stress and coping research. Researchers such as Lazarus and Folkman (1984, p. 327) are typical of many who view overt support mobilization, that is, the planned seeking, obtaining and utilizing of helpful social support, to be a positive coping strategy employed by individuals in response to a specific stressful event. In line with the position of stress and coping researchers (e.g., Gore, 1985; Lazarus and Folkman, 1984), we contend that support mobilization is an active coping response to perceived work stress. Employees overly seek, obtain and utilize helpful support from others. Although a functional view of support mobilization is tacitly acknowledged in the coping literature, the majority has not covered a range of supportive functions, nor has it explicitly encompassed the dimension of different sources of support (e.g., Carver, Scheier, and Weintraub, 1989; Wills and Shinar, 2000; for an exception see Lawrence, 2006). Thus utilizing the social support literature, we further argue that the 'support' being mobilized in supportive transactions comes from a variety of sources within a person's social network and can serve different functions (House, 1981). Employees can seek emotional (e.g., shows of concern or listening to the individual's problems), informational (e.g., the provision of advice), instrumental (e.g., the provision of active help with regards to aid in kind, money, labor, time or modifying the environment), or appraisal support (e.g., the provision of information relevant to self-evaluation, in the form of affirmation, feedback and social comparison) from three primary source categories: their supervisor, colleagues or external 
non-work sources, such as their partner, family, friends (see House, 1981; Lawrence, 2006; Terry et al., 1995; Thoits, 1986).

In this way, we conceptualize work-related support mobilization as a superordinate construct, where supportive functions mobilized from specific sources represent the first-order factors, and the distinct sources of support reflect the second-order factors (see Figure 1; Edwards, 2001; Williams, Edwards and Vandenberg, 2003). Based on the source of support framework (Cohen and McKay, 1984; Thoits, 1986), it is expected that individuals mobilize a distinctive pattern of supportive functions from each source of support. Past work by Lawrence et al. (2007) has successfully adopted and operationalized this multidimensional conceptualization of support with regards to perceptions of work support availability. It is this framework that we use in our research.

Insert Figure 1

\subsection{The role of support mobilization in shaping organizational outcomes}

Consistent with stress and coping theory (Lazarus and Folkman, 1984), empirical research in the occupational domain reveals that support mobilization directly influences workplace perceptions and behaviors. For example, researchers have found that global support mobilization is positively related to job satisfaction (Koleck, Bruchon-Schweiter, Thiebaut, Dumartin and Sifakis, 2000; Welbourne, Eggerth, Hartley, Andrew, and Sanchez, 2007). Chiaburu, Marinova, and Lim (2007) found that support mobilization was positively correlated with interpersonal helping behaviors, a facet of organizational citizenship behaviors. In related research, researchers have found that support-related concepts such as leader-member exchange (LMX) relationships (Bernerth et al., 2007; Ilies, Nahrgang, and Moregeson, 2007) and perceptions of organizational support (Maertz, Griffeth, Campbell, and 
Allen, 2007; Randall, Cropanzano, Bormann and Birjulin, 1999) are positively related to organizational citizenship behaviors and turnover intentions.

The evidence linking emotional support mobilization in particular to organizational outcomes is limited. Zellars and Perrewe (2001) found that the mobilization of support about negative issues increased emotional burnout whereas the mobilization of support about positive issues results in lower emotional burnout. Morrison (2004) reported that work-based friendship opportunities (which would involve reciprocal emotional support mobilization behaviors; see Wills and DePaulo, 1991) was positively correlated with job satisfaction and negatively correlated with turnover intentions. Other related evidence comes from what some researchers call emotional approach coping (i.e., emotional expression). Ashford (1988) found that emotional approach coping (linked to support mobilization, significantly reduced the effects of stress on employees undergoing organizational change, but found no effect for information support mobilization (see also Stanton, Kirk, Cameron and Danoff-Burg, 2000).

Overt information and feedback acquisition influences both job satisfaction and turnover intentions (Cooper-Thomas and Anderson, 2002; Wanberg and Kammeyer-Mueller, 2000). Research suggests that new employees seek information and feedback to reduce uncertainty about their job role and their interpersonal behavior within the context of new organizational norms and this, in turn, positively influenced their job satisfaction, performance and turnover intentions (Ashford, 1986; Morrison, 1993). Saks and Ashforth (1997) found that these relationships hold when information or feedback is sought from either supervisors or colleagues, whilst other researchers report differential mobilization patterns dependent on the source of support (Callister, Kramer, and Turnam, 1999; Morrison, 1993).

In the present article, from the theory and combined evidence presented above, it is expected that support mobilization constructs, operationalized in terms of both distinct supportive functions and distinct sources, would show differential correlation patterns with 
the organizational outcomes discussed (job satisfaction, turnover intention and organizational citizenship behaviors).

\subsection{Existing measures of support mobilization applicable to the work context}

The literature reveals some inconsistency in the operationalization of the solicited support mobilization construct. A review of the literature suggests only two primary approaches to the measurement of the construct. The first, which has not been widely used, is a measure constructed by Eckenrode (1983) which focuses on five event areas (neighbourhood, family relationships, health, work and finances) and asks respondents to count the number of people who aided the respondent in each event area within the previous year. Thus, the support mobilization measure represents the mean number of contacts per event. From this description alone, we contend that this measure does not assess the concept of support mobilization, but rather the concept of received support, or as Gore (1985) coins it, a social contact variable.

The second approach to support mobilization originates with the stress and coping work of Lazarus and Folkman (1984) and their Ways of Coping Questionnaire (WOCQ). This questionnaire covers the degree to which a variety of coping strategies are enacted when individuals are confronted with a stressful situation. The items themselves are generalized and independent of any reference to a potential source of stress. Researchers tend to specify a specific coping episode or specific period of time in the preamble in order to tap situational behavioral responses, as opposed to a dispositional coping style (i.e., what a person usually does under stress; Carver et al., 1989; O’Driscoll and Cooper, 1996). The compound support mobilization measure consists of 7 items that measure efforts to obtain informational and emotional support from others, although each of the different mobilization functions is not represented by an equal number of items. Subsequent research shows that the support mobilization measure consistently produces a reliable $(.65-.85)$ one-factor solution that 
predominantly consists of 6 items of virtually identical content (e.g., Aldwin and Revenson, 1987; Edwards and Baglioni, 1993; Masel et al., 1996).

The COPE Scales, developed by Carver et al. (1989), were devised to overcome the deficiencies of the WOCQ and to provide a more theoretically rigorous approach to conceptualizing coping strategies. The researchers propose two separate scales for support mobilization, 4 items reflecting seeking social support for instrumental/informational reasons and 4 items reflecting seeking social support for emotional reasons. Whilst a factor analysis of these items produced a single factor structure combining both scales (a simple correlation between the two composite scales was $r=.69)$, Carver et al. (1989) argue that it is still important to distinguish between the two support mobilization functions for predicting outcomes. From the review of the WOCQ and COPE above, it is clear that existing measures from the coping field are limited in scope as they are not source specific and at best only assess two supportive functions, emotional and informational support.

Literature in the area of feedback and information seeking during workplace socialization also provides measurement options for assessing some aspects of informational and appraisal support mobilization. Adapting the work of Ashford (1986), Morrison (1993) developed a scale assessing five different types of information and feedback seeking (technical information, referent information, normative information, performance feedback and social feedback) in the context of a variety of seeking behaviors (e.g., direct supervisor inquiry, experienced peer inquiry, other newcomer inquiry, observations, monitoring supervisors, monitoring co-workers, consulting written sources). Participants are asked to indicate the frequency with which they had engaged in a variety of seeking behaviors. Although a very useful measure, we argue that the Morrison (1993) scale is too focused on informational and appraisal support (House, 1981) for our purposes and its emphasis on frequency of contact differentiates this from the scale we develop in this article. 
Based on this review of existing measures, there is a clear need for a comprehensive measure that aligns with a multidimensional social mobilization concept in order to account for a range of supportive functions, while at the same time identifying the source of that support, from a range of alternatives inside and outside the workplace. We argue that the Lawrence et al. (2007) inventory reviewed below provides the best template on which to proceed with this task.

\subsection{Support Mobilization for Work Stressors (SMWS) Inventory development}

A measure of social support that is multidimensional in nature and applicable to a variety of work-related contexts is the Support Appraisal for Work Stressors (SAWS) inventory (Lawrence et al., 2007). The SAWS assesses perceptions of support availability (how much respondents can rely on others for support) for work-related problems, from both a functional and source perspective. It consists of 12 items, 3 items for each of the four supportive functions (emotional, informational, instrumental, appraisal). Respondents rate each item (e.g., How much can you rely on your ... to help you feel better when you experience work-related problems?) on a 4 -point scale $(1=$ not at all, $4=$ very much $)$ three times, with reference to 3 sources of support: direct supervisor, work colleagues and people outside work (partner/family/friends), thus producing a measure of four supportive functions for each of the three sources of support (12 variables). Internal consistency reliability for the 12 subscales is reported to range from $.76-.90$ (Lawrence et al., 2007). The inventory is also reported to show evidence of content validity, construct replication across samples, discriminant and criterion-related validity, and predictive validity. Clearly, although this is a significant measure, it only assesses the perceptions of available support (i.e. the extent of the support network) and not whether that support is mobilized.

The Support Mobilization for Work Stressors (SMWS) inventory developed in this research is based on a scale items first established by Lawrence et al. (2007) in their Support 
Appraisal for Work Stressors (SAWS) inventory. The SMWS measure consists of 12 items, which assess the four functions of perceived available support: Emotional, Informational, Instrumental, and Appraisal (3 items per function). Respondents respond to each item (e.g., "How often have you approached your (identify source of support) to help you feel better when you experience work-related problems?") on a 4-point scale ( 1 = “not at all" and $4=$ “often”) three times, once for each source of support: Supervisor, Colleagues, Non-work people (partner, family, friends). The 12 items in the support mobilization inventory contain exactly the same content as the perceived available support inventory items. However, rather than being asked to respond to the item with regards to how much they could rely on a source for a supportive function, the items were adapted to ask the respondent how often they approached a source for a supportive function. The scale anchors were also changed.

The idea of having an identical semantic core in items and using a referent shift (in either the start of the item or in the instructions) to denote a change in focus has been considered a legitimate approach and used in the prior measurement of social support constructs (see Bowling, Beehr and Swader, 2005; Heitzmann and Kaplan, 1988; Wills and Shinar, 2000). For instance, a range of authors have developed item inventories with two different instruction sets to enable the assessment of supportive functions from different perspectives (Fukada, Jou, Tozuka, and Higuchi, 2001; Jou and Fukada, 1997; Vaux et al., $1986,1987)$.

Instructions to respondents, adapted from Lawrence et al. (2007), were the following: "Please respond to each question by circling a number from the rating scale below in all three columns. In this way, for each question, you will rate separately your immediate supervisor, your work colleagues and your partner/family/friends. Think about your workplace in the last month. How often did you approach the people listed below when you experienced problems at work?" A month time span focus has been consistently used in the coping literature as a 
method to induce the recollection of situational responses to specific events as opposed to global perceptions of behavior (see Skinner et al., 2003; Wills and Shinar, 2000). A month is a preferred time span (as opposed to the "previous two weeks") to ensure the likelihood of a problematic work event occurring.

In summary, the SMWS assesses twelve constructs, which represents every possible combination of the three sources and four supportive functions. In the research studies to be presented next using the SMWS, we investigate further evidence for the conceptualization of support mobilization as distinguished by both supportive function and source. Following House's (1981) superordinate conceptualization of support, it is expected that each source of support provides four distinct supportive functions: emotional, informational, instrumental, and appraisal.

\section{Study 1}

The aim of Study 1 was to initially assess the factor structure dimensionality and reliability of the new SMWS inventory, and examine the criterion-related validity of the SMWS with organizational outcomes. The approach taken to assess the factor structure dimensionality of the SMWS took the form of three sets of confirmatory factor analyses. Using Anderson and Gerbing's (1988) recommended procedure we first conducted confirmatory factor analyses to determine the fit of each of the a priori source-based measurement models. We then conducted source-based nested model comparisons (see Mathieu and Farr, 1991) to determine whether a four factor solution best represented the data for each source of support mobilized. Finally, to confirm the dimensionality of the overall SMWS factor structure we assessed and compared a source-based superordinate measurement model with a function-based superordinate measurement model (Edwards, 2001; Williams et al., 2003). 
A major aim in developing this new inventory was to provide evidence of criterionrelated validity for SMWS. To do this we examined the partial bivariate correlations between the inventory constructs and two organizational attitudinal outcomes (job satisfaction, turnover intentions) and two organizational citizenship behaviors (interpersonal helping, individual initiative). Significant correlations between theoretically relevant variables and the construct of interest have been suggested to be an indication of the criterion-related validity of new constructs (Hinkin, 1998).

\subsection{Method}

\subsubsection{Procedure}

Data were collected through a cross-sectional survey from employees working for an Australian private-sector pathology company. One thousand, nine hundred and seventy-three employees received a self-administered survey via the pathology company's internal mail system and were requested to fill them in anonymously and return them to researchers via a postage-paid return envelope.

\subsubsection{Participants}

After deleting cases where systematic missing data were present for the variables of interest, 608 useable cases remained from the overall employee response of 657 (30\% response rate). Of the respondents, $84 \%$ were female. The mean age category of respondents was $41-45$ years, ranging from under 20 to over 60 years. Ten percent had completed postgraduate studies, $20 \%$ had completed graduate studies, $41 \%$ had completed a diploma, certificate or apprenticeship training and $29 \%$ had completed high school as their highest educational achievement. Respondents worked across all 10 possible staff classifications in the company (e.g., but not limited to, administration, pathology collection, laboratory assistants/ technicians, pathologist/medical officer, scientists). In terms of employment status, $50 \%$ were 
full-time, $46 \%$ part-time and $4 \%$ were casually employed. The mean tenure at the company was 8 years.

\subsubsection{Additional measures}

Turnover Intentions was assessed with 3 items from Colarelli (1984). Participants were asked whether they intended or were contemplating leaving their current job (e.g., I frequently think of quitting my job), on a 5-point Likert scale ( $1=$ strongly disagree, $5=$ strongly agree $)$. Whilst previous researchers have found Cronbach alpha's ranging from .75 to .77 (e.g., Saks and Ashforth, 1997; Schaubroeck, May, and Brown, 1994), in this study the alpha was .90.

Job Satisfaction was assessed with five items adapted from those used by Caplan, Cobb, French, Harrison and Pinneau (1975). The scale assesses generalized levels of job satisfaction (e.g., “All things considered, how satisfied are you with your job?”). Participants were asked to indicate their level of agreement with each statement, using a 5-point Likert scale $(1=$ very dissatisfied to 5 = very satisfied). Researchers have found this measure to demonstrate high levels of reliability, around the .90 level (c.f. Sargent and Terry, 1998, 2000). In this study, the alpha was .82 .

Two self-reported organizational citizenship behavior dimensions, Interpersonal Helping (e.g., I frequently adjust my work schedule to accommodate other employees' requests for time off) and Individual Initiative (e.g., I often motivate others to express their ideas and opinions) were assessed with 5 items each from Moorman and Blakely (1995). The measures used a 7 -point Likert scale $(1=$ strongly disagree, $7=$ strongly agree). Fields (2002) reported that reliability for interpersonal helping ranges between .67 and .78 , and for individual initiative, between .76 and .80 . In this study, the alphas were .76 and .82 , respectively.

As Gender, Age, Staff Classification and Negative Affect influences levels of job satisfaction, turnover and organizational citizenship behaviors (e.g., Kosmoski and Calkins, 
1986; Messer and White, 2006; Neubaurer, 1992), these variables were controlled for within the analysis of the data. Demographic data, gender $(1=$ male, $2=$ female $)$, age $(1=$ under 20 years to $10=$ over 60 years $)$ and staff classification $(1=$ employee, $2=$ manager $)$, were obtained from the survey. Negative Affect was assessed using ten items from Watson, Clark and Tellegen's (1988) PANAS scale. Respondents indicated the extent to which they generally experienced a range of negative mood states (e.g., Irritable), using a 5-point scale $(1=$ not at all to $5=$ extremely). Establishing the measurement properties of the PANAS using a sample of 1000 participants, Crawford and Henry (2004) reported a Cronbach alpha of .85 for this measure. In this study, the alpha was .87.

\subsection{Inventory dimensionality evaluation results}

Data screening for respondent errors and omissions was conducted prior to the analysis. Forty-nine cases were deleted where more than half the items were systematically missing from a particular support source scale. The remaining proportion of missing data for any particular scale item was $1 \%$ or less and after a careful examination, these missing data were deemed more likely to be missing at random (MAR; i.e., ignorable missingness) than missing not at random (MNAR) or missing completely at random (MCAR; Cohen and Cohen, 1983; Howell, 2007). In order to create unbiased parameter estimates, the remaining missing MAR data were replaced by values estimated by the EM imputation method (Gelman and Hill, 2006; Howell, 2007) in SPSS Statistics, Version 19. The resulting sample size was deemed adequate for performing further analyses (Kline, 2011).

All confirmatory factor analysis model estimations in Study 1 and Study 2 were conducted on covariance matrices, using the Robust Maximum Likelihood (ML) procedure in EQS 6.1 (Bentler and $\mathrm{Wu}, 2005$ ). Adhering to the recommendations of $\mathrm{Hu}$ and Bentler (1999), good model fit (versus acceptable, mediocre or poor fit) was deemed to be demonstrated when the CFI, IFI and NNFI were close to or exceeded .95, the RMSEA was 
equal to or less than .06 and the SRMR was equal to or less than .08. Corrected test statistics (the Satorra-Bentler rescaled chi-square statistic and the CFI Robust) are reported when assessing model fit using non-normal data (Kline, 2011).

\subsubsection{Source-based measurement models}

Anderson and Gerbing's (1988) recommended procedure was used to conduct confirmatory factor analyses to determine the dimensionality of each of the a priori source-based factor structures. We therefore assessed the fit of the four support functions separately for each source. The a priori four-factor measurement models for the supervisor $\left(\chi^{2}(48)=204.24, p<\right.$ $.001 ; \mathrm{CFI}=.96, \mathrm{IFI}=.96, \mathrm{NNFI}=.95, \mathrm{RMSEA}=.07, \mathrm{SRMR}=.03)$, colleague $\left(\chi^{2}(48)=\right.$ $200.48, \mathrm{p}<.001 ; \mathrm{CFI}=.97, \mathrm{IFI}=.97, \mathrm{NNFI}=.96, \mathrm{RMSEA}=.07, \mathrm{SRMR}=.03)$, and nonwork sources $\left(\chi^{2}(48)=238.69, \mathrm{p}<.001 ; \mathrm{CFI}=.95, \mathrm{IFI}=.95, \mathrm{NNFI}=.94, \mathrm{RMSEA}=.08\right.$, SRMR $=.05)$ all revealed good fit. For all three models, the CFI, IFI and NNFI indices were close to or reached .95 , the SRMR were below .06, the RMSEA were acceptable, the factor loadings were significant and high, and each functional subscale had a moderate to high level of reliability. Given the combined results, all models were deemed to show good fit (Anderson and Gerbing, 1988; Hu and Bentler, 1999). Table 1 presents the Cronbach's alphas and correlation table for the four functional subscales mobilized from each of the three sources of support.

\section{Insert Table 1}

\subsubsection{Source-based model comparisons}

As can be seen in Table 1, the subscale functions within each source of support have moderate to high correlations with one another. These correlations may be suggestive of multicollinearity and therefore a lack of discriminant validity amongst the functional subscales within each separate source of support. To verify that the four-factor structure, 
consistent with our conceptualization, was the best representation of the items in the SMWS, all possible alternative nested models were estimated for each source of support and chisquare comparisons were conducted against the relevant source-based a priori four-factor measurement model (see Mathieu and Farr, 1991). The nested measurement models included one-factor, 3 two-factor, and 6 three-factor structures. The two-factor models represented all possible pairings of the four support mobilization functions for a particular source. Similarly, the three-factor models represented all possible three-way combinations of the four supportive functions. The evaluation of these models, and the chi-square difference tests conducted to compare all of the alternative nested models to the a priori four-factor measurement model for each source of support, are shown in Tables 2 (Supervisor support), 3 (Colleague support), and 4 (Non-work support).

Results from the alternative model estimations and chi-square difference tests (Tables 2 , 3, and 4) confirm a four-factor supportive functional structure for the three sources of support mobilization. The four-factor solutions were as good, or better, than all alternative models. On balance, the model comparison analysis substantiates the notion that respondents did distinguish between the four supportive functions for each support mobilization source.

Insert Tables 2, 3, 4

\subsubsection{Superordinate measurement model comparisons}

As stated previously, our multidimensional conceptualization of support mobilization is consistent with a superordinate construct, where supportive functions from specific sources represent the first-order factors, and the distinct sources of support reflect the second-order factors. In order to further confirm the dimensionality of the overall SMWS factor structure we needed to assess and compare two further nested measurement models (c.f. Edwards, 2001; Williams et al., 2003). In this way we assessed the twelve SMWS constructs together in 
two alternative superordinate factor structures. The source-based superordinate factor structure $\left(\chi^{2}(51)=580.17, \mathrm{p}<.001 ; \mathrm{CFI}=.91, \mathrm{IFI}=.91, \mathrm{NNFI}=.90, \mathrm{RMSEA}=.13, \mathrm{SRMR}\right.$ $=.04$ ), consistent with our conceptualization, revealed a mediocre fit. The CFI, IFI and NNFI all reached .90 , the SRMR was below .08, and the factor loadings were moderately high (see Table 5). The RMSEA, however, was above .10. The overall measurement model was deemed to be a mediocre fit, given the combined results. Table 5 presents Cronbach's alpha coefficients and the standardized coefficient factor loadings for the SMWS inventory based on the source-based superordinate factor structure findings.

\section{Insert Table 5}

We also examined an alternative function-based superordinate model, in which the four supportive functions were represented as correlated second-order constructs, with sub-scale composites representing each of the sources at the first-order level. For example, informational support was represented as a second-order factor with three source variable indicators (informational support from supervisor, colleagues, and non-work people) formed from mean composites. Equivalent structures were defined for the other three functions. The alternative function-based superordinate factor structure $\left(\chi^{2}(48)=2867.68, \mathrm{p}<.001 ; \mathrm{CFI}=\right.$ $.53, \mathrm{IFI}=.53, \mathrm{NNFI}=.35, \mathrm{RMSEA}=.31, \mathrm{SRMR}=.19)$ revealed poor fit. A comparison of these two models revealed that a superordinate factor structure where functions form the firstorder constructs under second-order sources better represent the data $\left(\Delta \chi^{2}(3)=2287.51, p<\right.$ .001). This result provides support for our conceptualization that sources of support form the more fundamental distinction in respondents' mobilization of support.

\subsection{Criterion-related validity analysis of the SMWS with organizational outcomes}

The variables were formed from averaged composites. Gender $(\mathrm{M}=1.84, \mathrm{SD}=.37)$, Age $(\mathrm{M}=5.87, \mathrm{SD}=2.27)$, Staff Classification $(\mathrm{M}=1.07, \mathrm{SD}=.26)$ and Negative affect $(\mathrm{M}=$ 
2.00, $\mathrm{SD}=.50$ ) were controlled for in the partial correlational analysis. As indicated in Table 6, and as predicted, differential correlation patterns were present between the support mobilization constructs and the organizational outcomes. Significant negative correlations were present between all supervisor support mobilization constructs and turnover intentions, and all non-work support mobilization constructs were positively correlated with turnover intentions. Informational and instrumental support mobilized from supervisors were positively related to job satisfaction, whilst emotional support from colleagues and all four non-work support mobilization constructs were negatively related to job satisfaction.

Mobilizing appraisal support from all three sources and informational and instrumental support from supervisors and colleagues were positively related to interpersonal helping behaviors. With regards to the last OCB variable, whilst only mobilizing appraisal support from non-work people was positively related individual initiative behaviors, all supervisor and colleague support mobilization constructs were positively related to this variable. Overall, these results provide good support for the criterion-related validity of the SMWS constructs with respect to all four organizational outcomes.

\section{Insert Table 6}

\section{Study 2}

The aim of Study 2 was provide further evidence of the construct validity of the new SMWS inventory, by replicating the factor structure dimensionality and reliability found in Study 1, and assessing the degree of convergent and discriminant validity between the SMWS and the SAWS inventories. To assess whether the analysis results are a pervasive phenomenon and not an artifact of the particular sample used during data collection (see DeVellis, 1991), the confirmatory factor analyses conducted in Study 1 to assess factor structure dimensionality were repeated on data obtained from a second sample. 
To further confirm that a new measure has construct validity, researchers have argued that a new measure must show convergent validity (similarity) and discriminant validity (distinctiveness) with other existing measures that purport to assess theoretically similar concepts (Bernerth et al., 2007; Lawrence and Jordan, 2009). Convergent and discriminant validity is generally tested by examining correlations between the constructs of interest (Campbell and Fiske, 1959). In this study, we will examine the degree of convergent and discriminant validity between the new SMWS inventory and the SAWS (Lawrence et al., 2007) perceived available support inventory.

Theoretically, perceived available support is in the same nomological network as support mobilization, as both relate to the meta-concept of relational social support; however, the former is classified as a cognitive form of social support whereas support mobilization is a behavioral form (Schwarzer and Leppin, 1991). Further, perceptions of support availability are theorised to influence support mobilization behaviors when individuals are trying to deal with stressful situations (Lawrence, 2006). Empirically, little research has been conducted on the links between perceived available support and support mobilization but evidence reveals at best moderate correlations between the constructs (Heaney, House, Israel, and Mero, 1995; Lakey and Drew, 1997). Assessing convergent and discriminant validity between these two measures is important to demonstrate the efficacy of the SMWS. We expect that the SAWS perceived available support variables from a particular source will correlate at small to moderate levels with the SMWS support mobilization behavior variables from that matching source (e.g., a significant correlation between perceived available emotional support from supervisors and the mobilization of emotional support from supervisors, but not between perceived available emotional support from supervisors and the mobilization of emotional support from colleagues). 


\subsection{Method}

\subsubsection{Procedure}

Study 2's sampling frame consisted of 475 nurses from four departments (emergency, ICU, operating theatre, orthopaedics) in a large Australian public hospital. The data relating to the SAWS and SMWS inventories were collected in two different phases, separated by an interval of three weeks. At Time 1, a self-administered survey containing the SAWS inventory was distributed through the hospital's internal mail system to all 475 nursing staff. At Time 2, a self-administered survey containing the SMWS support mobilization inventory was distributed to the same nurses. At each point in time the surveys were completed anonymously by the nurses and returned to the researchers by reply-paid envelopes. Responses were matched using a unique identifier.

Given the need to maximize the returned sample size for the confirmatory factor analyses, the data relating to participants who filled out Time 2 were used in the replication dimensionality analyses. Alternatively, the data relating to the matched sample of participants who filled out both Time 1 and Time 2 were used in the convergent and discriminant validity analysis.

\subsubsection{Participants}

The nurse response rate for Part 1 and Part 2 of the survey was 197 (41\%) and 162 (35\%), respectively. In relation to the Time 2 replication sample, 155 respondents completed usable surveys out of a total of 475 potential respondents, yielding a response rate of $33 \%$. Of the respondents, $20 \%$ were male and $80 \%$ were female. Seven percent were nurse managers, $83 \%$ were clinical nurses and $10 \%$ were assistant nurses. In terms of employment status, $62 \%$ were full-time and $38 \%$ part-time. The mean age category of respondents was $31-35$ years. The mean tenure at the hospital was 6 years. 
One hundred and eighteen nurses completed usable responses to both Time 1 and Time 2 surveys that were able to be matched ( $25 \%$ response rate). Of the respondents, $17 \%$ were male and $83 \%$ were female. Twenty-five percent were nurse managers, $65 \%$ were clinical nurses and $10 \%$ were assistant nurses. Sixty-five percent worked full-time and $35 \%$ part-time. The mean age of respondents was 36-40 years. The mean tenure at the hospital was 6 years.

\subsubsection{Additional measures}

Perceived available support was assessed with Lawrence et al.'s (2007) SAWS inventory. As discussed earlier, the SAWS assesses perceptions of support availability (how much respondents can rely on others for support) for work-related problems, from both a functional and source perspective. Respondents rate each of the 12 items ( 3 items per supportive function; e.g., How much can you rely on your ... to help you feel better when you experience work-related problems?) with reference to 3 sources of support: direct supervisor, work colleagues and people outside work (partner/family/friends), on a 4-point scale ( 1 = not at all, $4=$ very much). The internal consistency reliabilities calculated for the SAWS and SMWS variables were acceptable (see Table 8).

\subsection{Inventory dimensionality replication results}

Data screening for respondent errors and omissions was conducted using the previously stated procedure. Nine cases were deleted due to systematic missing data. The remaining missing data ( $2 \%$ or less for each item) was deemed to be missing at random (MAR) and therefore this missing data were able to be replaced by values estimated by the EM imputation method (Gelman and Hill, 2006; Howell, 2007) in SPSS Statistics, Version 19. The resulting sample size was deemed adequate for performing further analyses (Kline, 2011).

Fit indexes and cutoff values used when conducting confirmatory factor analyses adhered to recommendations of $\mathrm{Hu}$ and Bentler (1999). These researchers acknowledge that their cited cutoffs for NNFI and RMSEA are too stringent when the sample size is less than 250. Given 
that the replication sample is less than 200, we applied a more liberal cutoff value of .90 for the NNFI and adapted Browne and Cudeck's (1993) suggested cutoffs for the RMSEA, so that values of .08 and below demonstrate good model fit, and values of .10 and below demonstrate acceptable fit. Corrected test statistics (the Satorra-Bentler rescaled chi-square statistic and the CFI Robust) were again reported to account for non-normal data.

\subsubsection{Source-based measurement models}

Confirmatory factor analyses again followed the procedure recommended by Anderson and Gerbing (1988) and outlined in section 2.2.1. Replication analyses assessing the four-factor model for each source of support revealed comparable results to the evaluation analyses of Study 1. The four-factor measurement models for the supervisor $\left(\chi^{2}(48)=70.06, p=.021\right.$; $\mathrm{CFI}=.98, \mathrm{IFI}=.98, \mathrm{NNFI}=.97, \mathrm{RMSEA}=.06, \mathrm{SRMR}=.04)$, colleague $\left(\chi^{2}(48)=88.94, \mathrm{p}\right.$ $<.001 ; \mathrm{CFI}=.95, \mathrm{IFI}=.95, \mathrm{NNFI}=.94, \mathrm{RMSEA}=.07, \mathrm{SRMR}=.05)$, and non-work sources $\left(\chi^{2}(48)=74.66, \mathrm{p}=.008 ; \mathrm{CFI}=.96, \mathrm{IFI}=.97, \mathrm{NNFI}=.95, \mathrm{RMSEA}=.06, \mathrm{SRMR}=.05\right)$ all revealed good fit. For all three models, the CFI, IFI and NNFI were close to or exceeded .95, the SRMR were below .06, the RMSEA were good, the factor loadings were significant and high and, as seen in Table 7, each functional subscale had a moderate to high level of reliability. Given the combined results, the three source measurement models were deemed to demonstrate good fit. Table 7 presents the Cronbach's alpha reliabilities and correlation table for the four functional subscales within each of the three sources of support.

Insert Table 7

\subsubsection{Source-based model comparisons}

Similar to Study 1's source-based measurement model findings, the subscale functions within each source of support in Study 2 had moderate to high correlations with one another (see Table 7). To verify our conceptualization of the four-factor measurement model structure for 
all three sources, all possible alternative nested models were again estimated for each source of support and chi-square comparisons were conducted against the relevant source-based $a$ priori four-factor measurement model (Mathieu and Farr, 1991). This replication analysis also supported the four-factor measurement model structure for all three sources of support (contact the authors for further details).

\title{
3.2.3 Superordinate measurement model comparisons
}

In order to further confirm the dimensionality of the overall SMWS factor structure we assessed and compared two further nested measurement models (c.f. Edwards, 2001; Williams et al., 2003). In this way, we again assessed the twelve SMWS constructs together in two alternative superordinate factor structures. The analyses revealed comparable results to the superordinate analyses conducted in Study 1. The source-based superordinate factor structure $\left(\chi^{2}(51)=197.10, \mathrm{p}<.001 ; \mathrm{CFI}=.90, \mathrm{IFI}=.90, \mathrm{NNFI}=.86, \mathrm{RMSEA}=.13, \mathrm{SRMR}\right.$ $=.06)$, consistent with our conceptualization, revealed a mediocre fit. The factor loadings were moderately high and the SRMR was good, the CFI and IFI were only acceptable, with the NNFI and RMSEA being mediocre. Although the chi-square statistic was still significant, the overall measurement model was deemed to be a mediocre fit, given the combined results. The alternative function-based superordinate factor structure $\left(\chi^{2}(48)=651.79, \mathrm{p}<.001\right.$; CFI $=.57, \mathrm{IFI}=.57, \mathrm{NNFI}=.41, \mathrm{RMSEA}=.19, \mathrm{SRMR}=.29)$, revealed poor fit. The CFI, IFI and NNFI failed to reach even .60, the RMSEA was .19 and the SRMR was .29. As for Sample 1, a comparison of these two models based on Sample 2 data clearly revealed that a superordinate factor structures where functions form first-order constructs under second-order sources better represent the data $\left(\Delta \chi^{2}(3)=454.69, p<.001\right)$.

\subsection{Convergent and discriminant validity analysis of the SMWS with the SAWS}

\author{
Insert Table 8
}


As indicated in Table 8, bivariate correlations between the four perceived available supportive functions and four support mobilization functions, matched for supervisor source, were significant but small, ranging from $r=.18$ to .26 . Bivariate correlations between the perceived available supportive functions and the support mobilization functions, matched for colleague source, were significant but small, ranging from $r=.22$ to .36 . Bivariate correlations between the perceived available supportive functions and the support mobilization functions, matched for non-work source, were significant and small to moderate, ranging from $r=.27$ to .42 .

In addition to the predicted significant correlations, perceived available emotional support from non-work sources was significantly correlated to each of the supervisor support mobilization functions (ranging from $r=.21$ to .24 ) and appraisal support mobilized from colleagues $(r=.23)$, and perceived available appraisal support from non-work sources was significantly correlated with informational support mobilized from supervisors $(r=.19)$. Given that the significant correlations found were small to moderate, with the highest correlation being $r=.42$, the results overwhelmingly provide support for both the convergent and discriminant validity of the new SMWS inventory as compared to the existing SAWS inventory. We therefore argue that the multidimensional support mobilization variables that the SMWS is assessing are related to, but conceptually distinct with multidimensional perceptions of support availability assessed by the SAWS.

\section{Discussion}

This program of research has developed a new multidimensional conceptualization and operationalization of support mobilization by bringing together the coping and social support literatures. As there is no adequate measure of support mobilization that is assessed from both a functional and source perspective, and that is applicable to the workplace context, a new measure was developed and validated: the Support Mobilization for Work Stressors (SMWS) inventory. The results of two studies reveal sound evidence for the psychometric properties of 
the SMWS measure. The new inventory showed evidence of reliability, construct validity (factor structure dimensionality, construct replication across samples, convergent and discriminant validity with the SAWS inventory), and criterion-related validity with outcome variables (job satisfaction, turnover intentions, interpersonal helping, and individual initiative).

\subsection{Contribution to theory and practice}

Significantly, the findings of our research validate the need for a more comprehensive conceptualization of support mobilization. Clearly, the analysis contained in Table 8 demonstrates that there is a clear distinction between perceived available support and the actual mobilization of that support. To more fully understand the conceptual structure and role of support mobilization, the current research needed to utilize and combine both coping theory and social support theory. The conceptualization framework that emerged proposes that work-related support mobilization is a superordinate concept, where distinct supportive functions are mobilized from different sources of support. A strength of the SMWS inventory is that the findings around the dimensionality of the new measure provide evidence for the construct validity of the conceptualization of support mobilization, distinguished by both supportive function and source. The results confirm House's (1981) conceptualization that for each source of support there are four distinct supportive functions. Additionally, consistent with the source of support framework (Cohen and McKay, 1984; Thoits, 1986), individuals in our studies were mobilizing distinctive supportive characteristics from each source of support.

The research presented here has implications for theory development, research practice and management practice. At a broad theoretical level, the use of the SMWS inventory enables a more systematic and comprehensive exploration of the role of support mobilization as a coping response in relation to work stressors. Currently, the research in this area is limited. Convergent and discriminant validity analyses with the SAWS inventory revealed 
that perceptions of available support are related to matched-source support mobilization behaviors. The criterion-related validity analyses found that the 12 support mobilization constructs are differentially related to organizational outcomes such as job satisfaction, turnover intentions, and the organizational citizenship dimensions of interpersonal helping and individual initiative. Extending the theoretical work of Gore (1985), it would also be of value to expand upon the conceptual framework outlined in the current research. For instance, future research might explore the moderating influence of specific workplace stressors on the relationship between multidimensional perceived available support constructs (using the SAWS; Lawrence et al., 2007) and support mobilization constructs (using the SMWS).

In terms of research practice, the new inventory provides researchers and practitioners with a short, efficient tool for measuring the degree of support being mobilized in organizations (Jones and Bright, 2001). Previous measures of support mobilization have not overtly assessed mobilization sources at all (Carver et al., 1989). For management practice, the findings of the various studies highlight that employees seek support from those they know both inside and outside the workplace to cope with work stressors.

Not surprisingly, mobilizing supervisor support is linked to less turnover and greater helping behaviors. Given that support provision plays a central role in frontline supervisors' jobs (Callan and Lawrence, 2007), HR managers need to emphasize the importance of effective supportive communication and guidance, and adequately train supervisors for this task. Significantly, when support is sought from work colleagues this can be linked to greater OCBs. Clearly, these results substantiate the need for the establishment of a constructive support environment where employees feel that they can mobilize support from a ready network of colleagues. In part, HR managers can achieve this aim using employee socialization programs, team building programs and co-mentoring support groups that are focused on improving collaborative communication and workplace relationships (Giga, 
Noblet, et al., 2003; van der Hek and Plomp, 1997). Finally, when support is sought from non-work sources, employees are more likely to leave and have less job satisfaction. If the organization finds that employees are turning to non-work people for support, then this may be also a signal that the organization needs to proactively address workplace stressors.

\subsection{Limitations and future directions}

The most serious limitation of this research is the presence of moderate bivariate correlations between supportive functions within each source of support, which is suggestive of a lack of discriminant validity. This phenomenon is not uncommon in past research.

Theoretically, the conceptual overlapping of supportive functions mobilized from particular sources of support is to be expected to some degree (c.f. Gore, 1985; Wills and Shinar, 2000). Empirically, other multi-functional measures of social support have also reported moderate correlations between functions (e.g., Carver et al., 1989; Lawrence et al., 2007). In our studies, all alternate models tested were not significantly better than the four factor model. The four factor model demonstrated good fit within each source of support across two samples, and there was a differential pattern of criterion-related findings for the four supportive functions within each source of support. On balance, therefore, we argue there is evidence to support our conceptualization that for each source of support, individuals' can mobilize four different supportive functions.

The findings from criterion-related validity tests were limited by the cross-sectional data collection procedure undertaken to collect the survey data. As a result, common method variance threatens the validity of these results (Podsakoff, MacKenzie, Lee and Podsakoff, 2003). In line with Podsakoff et al.'s (2003) recommendations, a measure of trait negative affect was included as one of the control variables to reduce the strength of bivariate correlations between the support mobilization and outcome measures. Additionally, content 
distinct measures were employed to reduce the prevalence of the consistency motif. Other potential sources of common method variance, however, were not accounted for.

Despite these issues, however, the results from this program of research provide good initial evidence for the construct validity of the support mobilization inventory as consisting of four support mobilization functions for each source of support. Future research needs to further assess the construct validity of the inventory using different sample compositions and organizational contexts. Given that the role of support mobilization as a coping response has been largely overlooked in the occupational stress literature, future research should also assess the degree to which differing stressor antecedents and moderating variables such as supportive cultures (e.g., Sarros, Gray, Densten and Cooper, 2005) can be linked to SMWS mobilization behaviors from work sources. Further predictive validity of the SMWS inventory in relation to other organizational outcomes such as organizational commitment and job performance also needs to be conducted.

\section{References}

Aldwin CM and Revenson TA (1987) Does coping help? A reexamination of the relation between coping and mental health. Journal of Personality and Social Psychology 53: 337348.

Anderson JC and Gerbing DW (1988) Structural equation modeling in practice: A review and recommended two-step approach. Psychological Bulletin 103: 411-423.

Anderson MH (2008) Social networks and the cognitive motivation to realize network opportunities: A study of managers' information gathering behaviors. Journal of Organizational Behavior 29: 51-78.

Ashford SJ (1986) Feedback-seeking in individual adaptation: A resource perspective. Academy of Management Journal 29: 465-487.

Ashford SJ (1988) Individual strategies for coping with stress during organizational transitions. Journal of Applied Behavioral Science 24: 19-36.

Bentler PM and Wu EJC (2005) EQS 6.1 - Structural equation modeling software for windows. Encino, CA: Multivariate Software, Inc.

Bernerth JB, Armenakis AA, Field HS, Giles WF and Walker HJ (2007) Leader-member social exchange (LMSX): Development and validation of a scale. Journal of Organizational Behavior 28: 979-1003.

Bowling NA, Beehr TA and Swader WM (2005) Giving and receiving social support at work: The roles of personality and reciprocity. Journal of Vocational Behavior 67: 476-489.

Browne MW and Cudeck R (1993) Alterative ways of assessing model fit. In: Bollen KA and Long JS (eds) Testing structural equation models. Newbury Park: Sage, 136-162 
Callister RR Kramer MW and Turnam DB (1999) Feedback seeking following career transitions. Academy of Management Journal 42: 429-438.

Callan VJ and Lawrence SA (2009) Building employee engagement, job satisfaction, health and retention. In: Cartwright S and Cooper CL (eds) The Oxford handbook of organizational well being. Oxford, UK: Oxford University Press, 411-438

Campbell DT and Fiske D (1959) Convergent and discriminant validation by the multitraitmultuimethod matrix. Psychological Bulletin, 56: 81-105.

Caplan RD, Cobb S, French JR, Harrison RV and Pinneau SR (1975) Job demands and worker health: Main effects of occupational differences. KHEW (NIOSH) publication. Cincinnati: National Institute of Occupational Safety and Health, 75-160

Carver, C. S, Scheier MF and Weintraub JK (1989) Assessing coping strategies: A theoretically based approach. Journal of Personality and Social Psychology 56: 267-283.

Chiaburu DS, Marinova SV and Lim AS (2007) Helping and proactive extra-role behaviors: The influence of motives, goal orientation, and social context. Personality and Individual Differences 43: 2282-2293.

Cohen J and Cohen P (1983) Applied multiple regression/correlation for the behavioral sciences $\left(2^{\text {nd }}\right.$ ed). Hillsdale, NJ: Erlbaum.

Cohen S and McKay G (1984) Social support, stress, and the buffering hypothesis: A theoretical analysis. In: Baum A, Singer GE and Taylor SE (eds) Handbook of psychology and health (Vol. 4). Hillsdale, NJ: Erlbaum, 253-268

Cohen S and Wills TA (1985) Stress, social support, and the buffering hypothesis. Psychological Bulletin 98: 310-357.

Colarelli J (1984) Methods of communication and mediating processes in realistic job previews. Journal of Applied Psychology 69: 633-642.

Cooper-Thomas H and Anderson N (2002) Newcomer adjustment: The relationship between organizational socialization tactics, information acquisition and attitudes. Journal of Occupational and Organizational Psychology 75: 423-437.

Crawford JR and Henry JD (2004) The positive and negative affect schedule (PANAS): Construct validity, measurement properties and normative data in a large non-clinical sample. British Journal of Clinical Psychology 43: 245-265.

Cutrona CE, Suhr JA and MacFarlane R (1990) Interpersonal transactions and the psychological sense of support. In: Duck S and Silver RC (eds) Personal relationships and social support. Newbury Park: Sage, 30-45

DeVellis RF (1991) Scale development: Theory and applications. Newbury Park: Sage.

Dewe P, Cox T and Ferguson E (1996) Individual strategies for coping with stress at work: A review. In: Palmer S and Dryden W (eds) Stress management and counselling: Theory, practice, research and methodology. London: Cassell, 115-128

Eckenrode J (1983) The mobilization of social supports: Some individual constraints. American Journal of Community Psychology 2:509-523.

Eckenrode J and Wethington E (1990) The process and outcome of mobilizing social support. In: Duck S and Silver RC (eds) Personal relationships and social support. Newbury Park: Sage, 83-103.

Edwards JA, Webster S, Van Laar D and Easton S (2008) Psychometric analysis of the UK Health and Safety Executive's Management Standards work-related stress Indicator Tool. Work \& Stress 22: 96-107.

Edwards JR (2001) Multidimensional constructs in organizational behavior research: An integrative analytical framework. Organizational Research Methods 4: 144-192.

Edwards J and Baglioni A (1993) The measurement of coping with stress: Construct validity of the Ways of Coping Checklist and the Cybernetic Coping Scale. Work \& Stress 7: 1731 . 
Fields DL (2002) Taking the measure of work: A guide to validated scales for organizational research and diagnosis. Thousand Oaks: Sage.

Folkman S and Lazarus RS (1985) If it changes it must be a process: Study of emotion and coping during three stages of a college examination. Journal of Personality and Social Psychology 48: 150-170.

Fukada H, Jou YH, Tozuka T and Higuchi M (2001) Factor structures of perceived and actual social support for Chinese students in Japan. Hiroshima Psychological Research 1: 45-51.

Gelman A and Hill J (2006) Data analysis using regression and multilevel/hierarchical models (Analytical methods for social research series). Cambridge: Cambridge University Press.

Giga SI, Noblet AJ, Faragher B and Cooper CL (2003) The UK perspective: A review of research on organizational stress management interventions. Australian Psychologist 38(2): 158-164.

Gore S (1985) Social support and styles of coping with stress. In: Cohen S and Syme SL (eds) Social support and health. Orlando: Academic Press, 263-278

Guppy A, Edwards, JA, Brough P, Peters-Bean KM, Sale C and Short E (2004) The psychometric properties of the short version of the Cybernetic Coping Scale: A multigroup confirmatory factor analysis across four samples. Journal of Occupational and Organizational Psychology 77: 39-62.

Heaney CA, House JS, Israel BA and Mero RP (1995) The relationship of organizational and social coping resources to employee coping behaviour: A longitudinal analysis, Work \& Stress 9: 416-431.

Heitzmann CA and Kaplan RM (1988) Assessment of methods for measuring social support. Health Psychology 7(1): 75-109.

Hinkin TR (1998) A brief tutorial on the development of measures for use in survey questionnaires. Organizational Research Methods 1: 104-121.

House JS (1981) Work stress and social support. Sydney: Addison-Wesley.

Howell DC (2007) The analysis of missing data. In Outhwaite, W. \& Turner, S. Handbook of social science methodology. London: Sage, 208-224.

$\mathrm{Hu}$ L and Bentler PM (1999) Cutoff criteria for fit indexes in covariance structure analysis: Conventional criteria versus new alternatives. Structural Equation Modeling 6: 1-55.

Ilies R, Nahrgang JD and Morgeson FP (2007) Leader-member exchange and citizenship behaviors: A meta-analysis. Journal of Applied Psychology 92: 269-277.

Jones F and Bright J (2001) Social support. In: Jones F and Bright J (eds) Stress: Myth, theory and research. Upper Saddle River, NJ: Prentice Hall, 155-174.

Jou YH and Fukada H (2002) Stress, health, and reciprocity and sufficiency of social support: The case of university students in Japan. The Journal of Social Psychology 142(3): 353370.

Jou YH and Fukada H (1997) Stress and social in mental and physical health of Chinese students in Japan. Psychological Reports 81: 1303-1312.

Kline RB (2011) Principals and practice of structural equation modeling ( $3^{\text {rd }}$ ed.). New York: The Guilford Press.

Koleck M, Bruchon-Schweitzer M, Thiebaut E, Dumartin N and Sifakis Y (2000) Stress, coping, and burnout among French general practitioners. European Review of Applied Psychology 50: 309-14.

Kosmoski KA and Calkins JD (1986) Critical care nurses' intent to stay in their positions. Research in Nursing and Health 9: 3-10.

Lakey B and Drew JB (1997) A social-cognitive perspective on social support. In: Pierce GR, Lakey B, Sarason IG and Sarason BR (eds) Sourcebook of Social Support and

Personality. New York: Plenum Press, 107-139. 
Lawrence SA (2006) An integrative model of perceived available support, work-family conflict and support mobilisation. Journal of Management and Organization 12: 160-179.

Lawrence SA, Gardner J and Callan VJ (2007) The Support Appraisal for Work Stressors Inventory: Construction and initial validation. Journal of Vocational Behavior 70: 172204.

Lawrence SA and Jordan PJ (2009) Exploring the links between explicit and implicit measures of motivation. International Journal of Organizational Analysis 17: 103-120.

Lazarus RS and Folkman S (1984) Stress, appraisal and coping. New York: Springer Publishing Company.

Maertz CP, Griffeth RW, Campbell NS and Allen DG (2007) The effects of perceived organizational support and perceived supervisor support on employee turnover. Journal of Organizational Behavior 28: 1059-1075.

Masel CN, Terry DJ and Gribble M (1996) The effects of coping on adjustment: Reexamining the goodness of fit model of coping effectiveness. Anxiety, Stress, and Coping 9: 277-278.

Mathieu JE and Farr JL (1991) Further evidence for the discriminant validity of measures of organizational commitment, job involvement, and job satisfaction. Journal of Applied Psychology 76: 127-134.

Messer BAE and White FA (2006) Employees' mood, perceptions of fairness and organizational citizenship behavior. Journal of Business and Psychology 21: 65-82.

Morrison EW (1993) Newcomer information seeking: Exploring types, modes, sources and outcomes. Academy of Management Journal 36: 557-589.

Morrison R (2004) Informal relationships in the workplace: Associations with job satisfaction, organisational commitment and turnover intentions. New Zealand Journal of Psychology 33: 114-128.

Moorman RH and Blakely GL (1995) Individualism-collectivism as an individual difference predictor of organizational citizenship behavior. Journal of Organizational Behavior 16: 127-142.

Neubauer, P. (1992). The impact of stress, hardiness, home and work environment on job satisfaction, illness and absenteeism in critical care nurses. Medical Psychotherapy: An International Journal 5: 109-122.

O'Driscoll MP and Cooper LC (1996) Coping with work-related stress: A critique of existing measures and a proposal for an alternative methodology. In: Palmer S and Dryden W (eds) Stress management and counselling: Theory, practice, research and methodology. London: Cassell, 129-142.

Podsakoff PM, MacKenzie SB, Lee JY and Podsakoff NP (2003) Common method biases in behavioral research: A critical review of the literature and recommended remedies, Journal of Applied Psychology 88: 879-903.

Randall ML, Cropanzano R, Bormann CA and Birjulin A (1999) Organizational politics and organizational support as predictors of work attitudes, job performance, and organizational citizenship behavior. Journal of Organizational Behavior 20: 159-174.

Reis HT and Collins N (2000) Measuring relationship properties and interactions relevant to social support. In: Cohen S, Underwood LG and Gottlieb BH (eds) Social support measurement and intervention: A guide for health and social scientists. London: Oxford University Press, 136-192.

Saks AM and Ashforth BE (1997) Socialization tactics and newcomer information acquisition. International Journal of Selection and Assessment, 5: 48-61.

Salas E, Cooke NJ and Rosen MA (2008) On teams, teamwork, and team performance: Discoveries and developments. Human Factors 50: 540-547. 
Sargent LD and Terry DJ (1998) The effects of work control and job demands on employee adjustment and work. Journal of Occupational and Organizational Psychology 71: 219236.

Sargent LD and Terry DJ (2000) The moderating role of social support in Karasek's job strain model. Work \& Stress 14: 245-261.

Sarros JC, Gray J, Densten IL and Cooper B (2005) The organizational culture profile revisited and revised: An Australian perspective. Australian Journal of Management 30: 159-182.

Schaubroeck J, May DR and Brown FW (1994) Procedural justice explanations and employee reactions to economic hardship: A field experiment. Journal of Applied Psychology 79: 455-460.

Schwarzer R and Leppin A (1991) Social support and health: A theoretical and empirical overview. Journal of Social and Personal Relationships 8: 99-127.

Skinner EA, Edge K, Altman J and Sherwood H (2003) Searching for the structure of coping: A review and critique of category systems for classifying ways of coping. Psychological Bulletin 129: 216-269.

Stanton AL, Danoff-Burg S, Cameron CL and Ellis AP (1994) Coping through emotional approach: Conceptualization and confounding. Journal of Personality and Social Psychology 78: 1150-1169.

Stone AA and Neale JM (1984) New measure of daily coping: Development and preliminary results. Journal of Personality and Social Psychology 46: 892-906.

Sutherland V and Cooper CL (2000) Stress and the changing nature of work. In: ClementsCroome D (ed) Creating the productive workplace. New York: E \& FN Spon.

Terry DJ, Rawle R and Callan VJ (1995) The effects of social support on adjustment to stress: The mediating role of coping. Personal Relationships 2: 97-124.

Thoits PA (1986) Social support as coping assistance. Journal of Consulting and Clinical Psychology 54: 416-423.

van der Hek H and Plomp HN (1997) Occupational stress management programmes: A practical overview of published effect studies. Occupational Medicine 47(3): 133-141.

Vaux A, Phillips J, Holly L, Thomson B, Williams D and Stewart D (1986) The social support appraisals (SS-A) scale: Studies of reliability and validity. American Journal of Community Psychology 14(2): 195-219.

Vaux A, Riedel S and Stewart D (1987) Modes of social support: The Social Support Behaviors (SS-B) Scale. American Journal of Community Psychology 15(2): 209237.

Vitaliano PP, Russo J, Carr JE, Maiuro RD and Becker J (1985) The ways of coping checklist: Revision and psychometric properties. Multivariate Behavioral Research 20: 326.

Wall T and Wood S (2005) The romance of human resource management and business performance, and the case for big science. Human Relations 58(4): 429-462.

Wanberg CR and Kammeyer-Mueller JD (2000) Predictors and outcomes of proactivity in the socialization process. Journal of Applied Psychology 85: 373-385.

Watson D, Clark LA and Tellegen A (1988) Development and validation of brief measures of positive and negative affect: The PANAS scales. Journal of Personality and Social Psychology 54: 1063-1070.

Welbourne JL, Eggerth D, Hartley TA, Andrew ME and Sanchez F (2007) Coping strategies in the workplace: Relationships with attributional style and job satisfaction. Journal of Vocational Behavior 70: 312-325. 
Williams LJ, Edwards JR and Vandenberg RJ (2003) Recent advances in causal modeling methods for organizational and management research. Journal of Management 29: 903936.

Wills TA and DePaulo BM (1991) Interpersonal analysis of the help-seeking process. In: Synder CR (ed) Handbook of social and clinical psychology. New York: Peragmon Press, 350-375.

Wills TA and Shinar O (2000) Measuring perceived and received social support. In: Cohen S, Underwood LG and Gottlieb BH (eds) Social support measurement and intervention: $A$ guide for health and social scientists. London: Oxford University Press, 86-135.

Winefield AH (2002) Unemployment, underemployment, occupational stress and psychological well-being. Australian Journal of Management 27: 137-148.

Zellars KL and Perrewe PL (2001) Affective personality and the content of emotional social support: Coping in organizations, Journal of Applied Psychology 86:459-467. 
Table 1. Means, standard deviations, correlations and Cronbach's alpha reliabilities for Study $1^{\mathrm{a}}$

\begin{tabular}{|c|c|c|c|c|c|c|c|c|c|c|c|c|c|c|}
\hline Variable & M & SD & 1 & 2 & 3 & 4 & 5 & 6 & 7 & 8 & 9 & 10 & 11 & 12 \\
\hline \multicolumn{15}{|c|}{ Supervisor Support } \\
\hline 1. Emotional & 1.88 & .84 & $(.84)^{\mathrm{b}}$ & & & & & & & & & & & \\
\hline 2. Informational & 2.01 & .86 & .75 & $(.84)$ & & & & & & & & & & \\
\hline 3. Instrumental & 2.04 & .86 & .78 & .86 & $(.84)$ & & & & & & & & & \\
\hline 4. Appraisal & 1.63 & .73 & .81 & .78 & .80 & $(.81)$ & & & & & & & & \\
\hline \multicolumn{15}{|l|}{ Colleague Support } \\
\hline 5. Emotional & 2.35 & .85 & .41 & .33 & .35 & .35 & $(.83)$ & & & & & & & \\
\hline 6. Informational & 2.34 & .86 & .34 & .48 & .43 & .37 & .76 & $(.83)$ & & & & & & \\
\hline 7. Instrumental & 2.38 & .86 & .33 & .39 & .44 & .38 & .79 & .84 & $(.84)$ & & & & & \\
\hline 8. Appraisal & 1.91 & .81 & .37 & .37 & .39 & .50 & .79 & .73 & .78 & $(.82)$ & & & & \\
\hline \multicolumn{15}{|l|}{ Non-work Support } \\
\hline 9. Emotional & 2.46 & 1.04 & .18 & .16 & .17 & .20 & .38 & .28 & .29 & .32 & $(.89)$ & & & \\
\hline 10. Informational & 1.69 & .86 & .27 & .21 & .22 & .29 & .39 & .34 & .34 & .43 & .66 & $(.85)$ & & \\
\hline 11. Instrumental & 1.76 & .86 & .27 & .20 & .22 & .30 & .37 & .28 & .32 & .40 & .70 & .83 & $(.80)$ & \\
\hline 12. Appraisal & 1.87 & .91 & .21 & .18 & .19 & .27 & .39 & .33 & .37 & .46 & .77 & .78 & .78 & $(.83)$ \\
\hline
\end{tabular}

${ }^{\mathrm{a}} \mathrm{n}=608 .{ }^{\mathrm{b}}$ Figures in parentheses indicate inter-item reliabilities.

$p<.001$ for all $r>.15$. 
Table 2. Results of supervisor support mobilization model comparisons for Study $1^{\mathrm{a}}$

\begin{tabular}{|c|c|c|c|c|c|c|c|c|c|c|c|}
\hline Model & $\chi^{2 b}$ & $d f$ & $p$ & $\Delta \chi^{2}$ & $\Delta d f$ & RCFI & $\triangle \mathrm{CFI}$ & IFI & NNFI & SRMR & RMSEA \\
\hline 4-factor: Emot Inst Info Appr ${ }^{c}$ & 204.24 & 48 & $<.001$ & --- & --- & .96 & --- & .96 & .95 & .03 & .07 \\
\hline 3-factor: (Emot/Inst) Info Appr & 253.84 & 51 & $<.001$ & $49.60 * * *$ & 3 & .95 & .01 & .95 & .94 & .04 & .08 \\
\hline 3-factor: (Emot/Info) Inst Appr & 260.80 & 51 & $<.001$ & $56.56 * * *$ & 3 & .95 & .01 & .95 & .93 & .04 & .08 \\
\hline 3-factor: (Emot/Appr) Inst Info & 210.75 & 51 & $<.001$ & 6.51 & 3 & .96 & .00 & .96 & .95 & .04 & .07 \\
\hline 3-factor: Emot (Inst/Info) Appr & 211.71 & 51 & $<.001$ & 7.47 & 3 & .96 & .00 & .96 & .95 & .03 & .07 \\
\hline 3-factor: Emot (Inst/Appr) Info & 227.00 & 51 & $<.001$ & $22.76 * * *$ & 3 & .96 & .00 & .96 & .94 & .04 & .08 \\
\hline 3-factor: Emot Inst (Info/Appr) & 234.98 & 51 & $<.001$ & $20.74 * * *$ & 3 & .96 & .00 & .96 & .94 & .04 & .08 \\
\hline 2-factor: (Emot/Inst) (Info/Appr) & 262.37 & 53 & $<.001$ & $58.13 * * *$ & 5 & .95 & .01 & .95 & .94 & .04 & .08 \\
\hline 2-factor: (Emot/Info) (Inst/Appr) & 262.44 & 53 & $<.001$ & $58.20 * * *$ & 5 & .95 & .01 & .95 & .94 & .04 & .08 \\
\hline 2-factor: (Emot/Appr) (Inst/Info) & 218.90 & 53 & $<.001$ & $14.66^{* * *}$ & 5 & .96 & .00 & .96 & .95 & .04 & .07 \\
\hline 1-factor: (Emot/Inst/Info/Appr) & 263.65 & 54 & $<.001$ & $59.41 * * *$ & 6 & .95 & .01 & .95 & .94 & .04 & .08 \\
\hline
\end{tabular}

${ }^{\mathrm{a}} \mathrm{n}=608$.

${ }^{\mathrm{b}}$ Sartorra-Bentler $\chi^{2}$

${ }^{c}$ Emot $=$ Emotional support mobilization, Inst $=$ Instrumental support mobilization, Info $=$ Informational support mobilization, Appr $=$ Appraisal support mobilization 
Table 3. Results of colleague support mobilization model comparisons for Study $1^{\text {a }}$

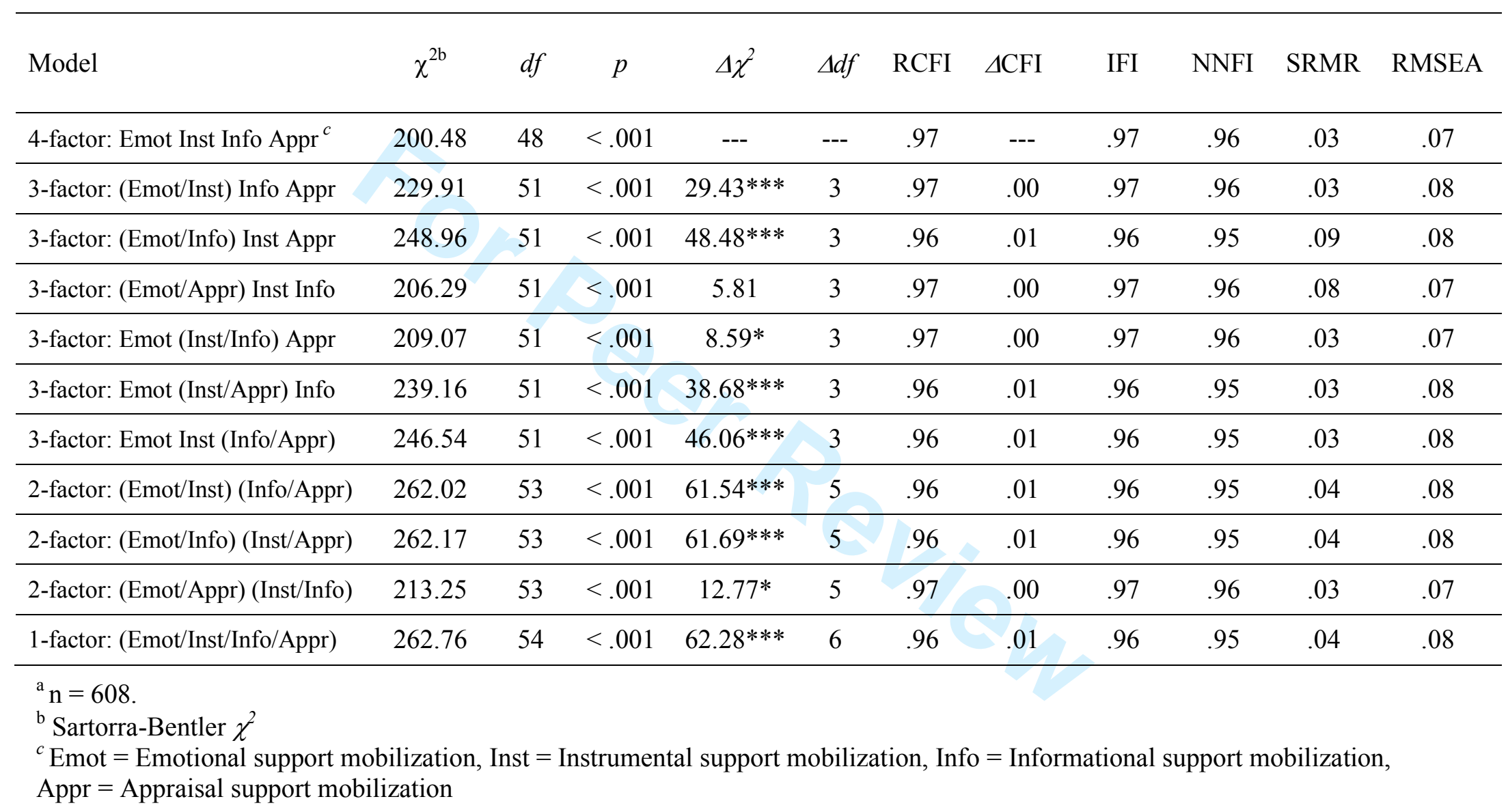


Table 4. Results of non-work support mobilization model comparisons for Study $1^{\text {a }}$

\begin{tabular}{|c|c|c|c|c|c|c|c|c|c|c|c|}
\hline Model & $\chi^{2 b}$ & $d f$ & $p$ & $\Delta \chi^{2}$ & $\Delta d f$ & RCFI & $\triangle \mathrm{CFI}$ & IFI & NNFI & SRMR & RMSEA \\
\hline 4-factor: Emot Inst Info Appr ${ }^{c}$ & 238.69 & 48 & $<.001$ & --- & --- & .95 & --- & .95 & .94 & .05 & .08 \\
\hline 3-factor: (Emot/Inst) Info Appr & 448.49 & 51 & $<.001$ & $209.80 * * *$ & 3 & .90 & .05 & .90 & .87 & .06 & .11 \\
\hline 3-factor: (Emot/Info) Inst Appr & 480.88 & 51 & $<.001$ & $242.19 * * *$ & 3 & .90 & .05 & .90 & .86 & .06 & .12 \\
\hline 3-factor: (Emot/Appr) Inst Info & 339.57 & 51 & $<.001$ & $100.88^{* * *}$ & 3 & .93 & .02 & .93 & .91 & .06 & .10 \\
\hline 3-factor: Emot (Inst/Info) Appr & 241.98 & 51 & $<.001$ & 3.29 & 3 & .95 & .00 & .95 & .94 & .10 & .08 \\
\hline 3-factor: Emot (Inst/Appr) Info & 274.16 & 51 & $<.001$ & $35.47 * * *$ & 3 & .95 & .00 & .95 & .93 & .05 & .09 \\
\hline 3-factor: Emot Inst (Info/Appr) & 303.36 & 51 & $<.001$ & $64.67 * * *$ & 3 & .94 & .01 & .94 & .92 & .05 & .09 \\
\hline 2-factor: (Emot/Inst) (Info/Appr) & 472.96 & 53 & $<.001$ & $234.27 * * *$ & 5 & .90 & .05 & .90 & .97 & .14 & .11 \\
\hline 2-factor: (Emot/Info) (Inst/Appr) & 486.32 & 53 & $<.001$ & $247.63^{* * *}$ & 5 & .89 & .06 & .89 & .87 & .06 & .12 \\
\hline 2-factor: (Emot/Appr) (Inst/Info) & 341.82 & 53 & $<.001$ & $103.13 * * *$ & 5 & .93 & .02 & .93 & .91 & .06 & .10 \\
\hline 1-factor: (Emot/Inst/Info/Appr) & 485.01 & 54 & $<.001$ & $246.32 * * *$ & 6 & .90 & .05 & .90 & .87 & .06 & .12 \\
\hline
\end{tabular}

${ }^{\mathrm{a}} \mathrm{n}=608$.

${ }^{\mathrm{b}}$ Sartorra-Bentler $\chi^{2}$

${ }^{c}$ Emot $=$ Emotional support mobilization, Inst $=$ Instrumental support mobilization, Info $=$ Informational support mobilization, Appr $=$ Appraisal support mobilization 
Table 5. Standardized confirmatory factor analysis coefficients and Cronbach's alpha coefficients from Study 1 source-based superordinate factor structure measurement model.

\begin{tabular}{lcc}
\hline Subscale Labels and Items & $\begin{array}{c}\text { Standardized } \\
\text { Coefficient }\end{array}$ & $\begin{array}{c}\text { Cronbach's } \\
\text { Alpha } \\
\text { Factor Loadings Coefficients }\end{array}$ \\
\hline
\end{tabular}

Emotional Support from Direct Supervisor

.84

MSEMOT1: How often have you approached your ... seeking help to feel better when you experience work-

related problems?

MSEMOT2: How often have you asked your ... to listen to you when you need to talk about work-related problems?

MSEMOT3: How often have you approached your ... for sympathy and understanding about your work-related problems?

Informational Support from Direct Supervisor

MSINFO1: How often have you approached your ... for suggestions on ways to find out more about a work situation that is causing you problems?

MSINFO2: How often have you asked your ... to share their experiences of a work problem similar to yours?

MSINFO3: How often have you asked your ... to provide information which helps to clarify your work-related problems?

Instrumental Support from Direct Supervisor

MSPRAC1: How often have you asked your ... for practical assistance when you experience work related problems?

MSPRAC2: How often have you asked your ... to spend time helping you resolve your work-related problems?

MSPRAC3: How often have you asked your ... for help when things get tough at work?

MSAPPR1: How often have you approached your ... for reassurance about your ability to deal with your workrelated problems?

MSAPPR2: How often have you approached your ... for acknowledgement of your efforts to resolve your workrelated problems?

MSAPPR3: How often have you approached your ... for help in evaluating your attitudes and feelings about your work-related problems? 


\begin{tabular}{cc} 
Standardized & Cronbach's \\
Coefficient & Alpha \\
Factor Loadings & Coefficients \\
\hline
\end{tabular}

Emotional Support from Colleagues

.83

MCEMOT $^{\mathrm{a}}$

.72

MCEMOT2

.78

.84

Informational Support from Colleagues

MCINFO1

.76

MCINFO2

.76

.81

Instrumental Support from Colleagues

MCPRAC1

.73

.82

.83

MCPRAC3

.82

.75

.81

.79

MCAPPR3

.89

.84

.87

.84

MNEMOT3

MNINFO1

MNINFO3

.81

Instrumental Support from Non-work People

MNPRAC1

Appraisal Support from Non-work People

MNAPPR2

MNAPPR3

Items worded as shown above for direct supervisor source.

Note: All factor coefficients significant at $\mathrm{p}<0.001$ 
Table 6. Means, standard deviations, partial correlations and Cronbach's alpha reliabilities for Study 1 criterion-related validity analysis ${ }^{\text {ab }}$

\begin{tabular}{|c|c|c|c|c|c|c|c|c|c|c|c|c|c|c|c|c|c|c|}
\hline Variable & Mean & $S D$ & 1 & 2 & 3 & 4 & 5 & 6 & 7 & 8 & 9 & 10 & 11 & 12 & 13 & 14 & 15 & 16 \\
\hline \multicolumn{19}{|l|}{ Predictors } \\
\hline \multicolumn{19}{|l|}{ Supervisor Support Mobil. } \\
\hline 1. Emotional & 1.88 & .84 & $(.84)^{\mathrm{c}}$ & & & & & & & & & & & & & & & \\
\hline 2. Informational & 2.01 & .86 & .76 & $(.84)$ & & & & & & & & & & & & & & \\
\hline 3. Instrumental & 2.04 & .86 & .79 & .86 & $(.84)$ & & & & & & & & & & & & & \\
\hline 4. Appraisal & 1.63 & .73 & .81 & .78 & .80 & $(.81)$ & & & & & & & & & & & & \\
\hline \multicolumn{19}{|l|}{ Colleague Support Mobil. } \\
\hline 5. Emotional & 2.35 & .85 & .41 & .34 & .37 & .35 & (.83) & & & & & & & & & & & \\
\hline 6. Informational & 2.34 & .86 & .34 & .48 & .45 & .37 & .75 & $(.83)$ & & & & & & & & & & \\
\hline 7. Instrumental & 2.38 & .86 & .32 & .40 & .45 & .38 & .78 & .84 & $(.84)$ & & & & & & & & & \\
\hline 8. Appraisal & 1.91 & .81 & .37 & .38 & .40 & .50 & .78 & .73 & .78 & $(.82)$ & & & & & & & & \\
\hline \multicolumn{19}{|l|}{ Non-work Support Mobil. } \\
\hline 9. Emotional & 2.46 & 1.04 & .17 & .16 & .16 & .19 & .36 & .26 & .27 & .29 & (.89) & & & & & & & \\
\hline 10. Informational & 1.69 & .86 & .26 & .21 & .22 & .28 & .37 & .33 & .32 & .41 & .65 & $(.85)$ & & & & & & \\
\hline 11. Instrumental & 1.76 & .86 & .26 & .20 & .21 & .30 & .35 & .27 & .30 & .39 & .69 & .83 & $(.80)$ & & & & & \\
\hline 12. Appraisal & 1.87 & .91 & .20 & .18 & .19 & .26 & .36 & .31 & .34 & .43 & .76 & .78 & .78 & $(.83)$ & & & & \\
\hline \multicolumn{19}{|l|}{ Criterions } \\
\hline 13. Turnover Intentions & 2.19 & 1.13 & -.14 & -.13 & -.12 & -.11 & .02 & -.04 & -.05 & -.04 & .18 & .07 & .10 & .10 & $(.90)$ & & & \\
\hline 14. Job Satisfaction & 3.68 & .79 & .05 & .10 & .08 & .07 & -.09 & -.02 & -.01 & -.02 & -.23 & -.15 & -.15 & -.14 & -.65 & $(.82)$ & & \\
\hline 15. OCB Helping Behaviors & 5.89 & .69 & .04 & .11 & .08 & .08 & .05 & .09 & .11 & .08 & .01 & .04 & .04 & .09 & -.15 & .25 & $(.76)$ & \\
\hline 16. OCB Personal Initiative & 5.34 & .69 & .11 & .11 & .11 & .12 & .18 & .18 & .19 & .18 & .05 & .06 & .07 & .11 & -.09 & .15. & .66 & $(.82)$ \\
\hline
\end{tabular}

${ }^{a}$ Partial correlations between variables were computed using $n=608$, controlling for Negative Affect, Gender, Age, and Staff Classification (effective $\mathrm{n}=602$ ).

${ }^{\mathrm{b}} p<.05$ for all $r>.07, p<.01$ for all $r>.10$ and $p<.001$ for all $r>.12$.

${ }^{\mathrm{c}}$ Figures in parentheses indicate inter-item reliabilities. 
Table 7. Means, standard deviations, correlations and Cronbach's alpha reliabilities for Study $2^{\text {ab }}$

\begin{tabular}{lllllllllllllll}
\hline Variable & Mean & $S D$ & 1 & 2 & 3 & 4 & 5 & 6 & 7 & 8 & 9 & 10 & 11 & 12 \\
\hline
\end{tabular}

\section{Supervisor Support Mobilization}

1. Emotional

2. Informational

3. Instrumental

4. Appraisal

\section{Colleague Support Mobilization}
5. Emotional
6. Informational
7. Instrumental

8. Appraisal

Non-work Support Mobilization

9. Emotional
10. Informational
11. Instrumental
12. Appraisal

$\begin{array}{ccc}1.79 & .72 & (.87)^{\mathrm{b}} \\ 1.83 & 73 & .70\end{array}$

$\begin{array}{cccc}1.83 & .73 & .70 & (.78)\end{array}$

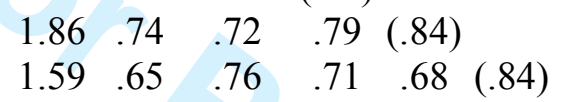

$\begin{array}{lllllll}2.37 & .71 & .38 & .30 & .29 & .29 & (.75)\end{array}$

$\begin{array}{llllllll}2.27 & .69 & .16 & .39 & .27 & .25 & .71 & (.70)\end{array}$

$\begin{array}{lllllllll}2.37 & .72 & .29 & .37 & .43 & .26 & .71 & .78 & (.79)\end{array}$

$\begin{array}{llllllllll}1.92 & .67 & .31 & .32 & .26 & .47 & .66 & .69 & .66 & (.74)\end{array}$

$\begin{array}{lllllllllll}2.56 & .91 & .17 & .31 & .28 & .27 & .35 & .38 & .39 & .43 & (.81)\end{array}$

$\begin{array}{llllllllllll}2.56 & .91 & .17 & .31 & .28 & .27 & .35 & .38 & .39 & .43 & (.81) & \\ 1.62 & .72 & .07 & .20 & .18 & .26 & .26 & .38 & .33 & .44 & .60 & (.78)\end{array}$

$\begin{array}{lllllllllllll}1.67 & .78 & .06 & .19 & .18 & .19 & .25 & .39 & .37 & .44 & .65 & .81 & (.81)\end{array}$

${ }^{\mathrm{a}} \mathrm{n}=155 .{ }^{\mathrm{b}}$ Figures in parentheses indicate inter-item reliabilities

$p<.05$ for all $r>.15, p<.01$ for all $r>.20$ and $p<.001$ for all $r>.25$. 
Table 8. Means, standard deviations, correlations and Cronbach's alpha reliabilities for Study 2 convergent and discriminant validity analysis ${ }^{\text {ab }}$

\begin{tabular}{|c|c|c|c|c|c|c|c|c|c|c|c|c|c|c|c|c|c|c|c|c|c|c|c|c|c|}
\hline Variables & Mean & $S D$ & 1 & 2 & 3 & 4 & 5 & 6 & 7 & 8 & 9 & 10 & 11 & 12 & 13 & 14 & 15 & 16 & 17 & 18 & 19 & 20 & 21 & 22 & 24 \\
\hline \multicolumn{26}{|l|}{ SAWS Inventory: Appraisal } \\
\hline 1. Perceived Emotional (Sup) & 2.77 & .89 & $(.88)^{\mathrm{c}}$ & & & & & & & & & & & & & & & & & & & & & & \\
\hline 2. Perceived Informational (Sup) & 2.60 & .89 & .89 & $(.87)$ & & & & & & & & & & & & & & & & & & & & & \\
\hline 3. Perceived Instrumental (Sup) & 2.64 & .87 & .87 & .85 & $(.88)$ & & & & & & & & & & & & & & & & & & & & \\
\hline 4. Perceived Appraisal (Sup) & 2.61 & .90 & .88 & .90 & .85 & $(.89)$ & & & & & & & & & & & & & & & & & & & \\
\hline 5. Perceived Emotional (Col) & 3.13 & .70 & .47 & .47 & .46 & .51( & $(.84)$ & & & & & & & & & & & & & & & & & & \\
\hline 6. Perceived Informational (Col) & 2.90 & .70 & .34 & .43 & .34 & .43 & .81 & $(.75)$ & & & & & & & & & & & & & & & & & \\
\hline 7. Perceived Instrumental $(\mathrm{Col})$ & 2.98 & .71 & .29 & .32 & .37 & .36 & .82 & .81( & $(.83)$ & & & & & & & & & & & & & & & & \\
\hline 8. Perceived Appraisal (Col) & 2.85 & .71 & .42 & .44 & .42 & .51 & .86 & .84 & .82( & $(.81)$ & & & & & & & & & & & & & & & \\
\hline 9. Perceived Emotional (Nwk) & 2.38 & .72 & .29 & .24 & .21 & .19 & .30 & .24 & .20 & .28( & $(.89)$ & & & & & & & & & & & & & & \\
\hline 10. Perceived Informational (Nwk) & 2.29 & .67 & .22 & .20 & .24 & .18 & .11 & .17 & .11 & .17 & .66( & $(.83)$ & & & & & & & & & & & & & \\
\hline 11. Perceived Instrumental (Nwk) & 2.39 & .70 & .24 & .23 & .25 & .21 & .14 & .16 & .13 & .24 & .72 & .86( & $(.83)$ & & & & & & & & & & & & \\
\hline 12. Perceived Appraisal (Nwk) & 1.96 & .70 & .28 & .21 & .21 & .21 & .19 & .18 & .14 & .27 & .85 & .76 & .80( & $(.86)$ & & & & & & & & & & & \\
\hline \multicolumn{26}{|l|}{ SMWS Inventory: Mobilization } \\
\hline 13. Emotional Mobil. (Sup) & 1.82 & .75 & .23 & .20 & .26 & .23 & -.04 & $-.10-$ & $-.03-$ & -.05 & .21 & .10 & .11 & .15 & $(.82)$ & & & & & & & & & & \\
\hline 14. Informational Mobil. (Sup) & 1.86 & .74 & .25 & .29 & .25 & .25 & .00 & .03 & $-.01-$ & -.01 & .24 & .07 & .14 & .19 & $.72($. & $(.78)$ & & & & & & & & & \\
\hline 15. Instrumental Mobil. (Sup) & 1.87 & .74 & .20 & .19 & .19 & .25 & -.01 & $-.05-$ & $-.01-$ & -.04 & .21 & .06 & .10 & .13 & .75 & $.82($. & $(.84)$ & & & & & & & & \\
\hline 16. Appraisal Mobil. (Sup) & 1.63 & .68 & .21 & .21 & .22 & .18 & -.02 & $-.07-$ & $-.05-$ & -.01 & .24 & .09 & .13 & .12 & .79 & .71 & .68 & $(.85)$ & & & & & & & \\
\hline 17. Emotional Mobil. (Col) & 2.38 & .72 & .00 & .07 & .09 & .07 & .29 & .32 & .31 & .27 & .06 & -.06 & -.06 & -.05 & .41 & .29 & .30 & .34 & $(.76)$ & & & & & & \\
\hline 18. Informational Mobil. (Col) & 2.29 & .67 & .01 & .07 & .04 & .04 & .28 & .36 & .34 & .32 & .16 & .03 & .10 & .13 & .21 & .37 & .27 & .28 & .73 & (.69) & & & & & \\
\hline 19. Instrumental Mobil. (Col) & 2.39 & .70 & -.02 & .01 & -.03 & -.03 & .24 & .26 & .30 & .22 & $.16-$ & -.01 & .04 & .08 & .28 & .33 & .37 & .25 & .72 & .79( & $(.78)$ & & & & \\
\hline 20. Appraisal Mobil. (Col) & 1.96 & .70 & .02 & .08 & .06 & .05 & .23 & .30 & .28 & .31 & .23 & .14 & .17 & .15 & .30 & .26 & .22 & .45 & .71 & .71 & .66( & $(.80)$ & & & \\
\hline 21. Emotional Mobil. (Nwk) & 2.57 & .94 & .09 & .12 & .05 & .05 & .10 & .17 & .07 & .11 & .38 & .29 & .36 & .37 & .20 & .34 & .32 & .28 & .40 & .43 & .43 & $.45($. & $(.84)$ & & \\
\hline 22. Informational Mobil. (Nwk) & 1.66 & .75 & .05 & .07 & -.02 & .03 & -.02 & .07 & .02 & .02 & .27 & .36 & .35 & .28 & .07 & .18 & .17 & .23 & .30 & .39 & .33 & .42 & .61( & $.78)$ & \\
\hline 23. Instrumental Mobil. (Nwk) & 1.74 & .82 & .10 & .10 & .04 & .07 & .00 & .07 & .03 & .04 & .31 & .36 & .41 & .34 & .04 & .18 & .19 & .17 & .30 & .42 & .41 & .43 & .68 . & $.82(.8$ & $.80)$ \\
\hline 24. Appraisal Mobil. (Nwk) & 1.90 & .85 & .17 & .16 & .12 & .10 & .03 & .12 & .04 & .09 & .33 & .39 & .42 & .38 & .16 & .29 & .23 & .31 & .32 & .45 & .41 & .50 & .75 & .75 . & $.79(.78)$ \\
\hline
\end{tabular}

${ }^{\mathrm{a}} \mathrm{n}=118 .{ }^{\mathrm{b}} p<.05$ for all $r>.17, p<.01$ for all $r>.22$ and $p<.001$ for all $r>.28{ }^{\mathrm{c}}$ Figures in parentheses indicate inter-item reliabilities. 


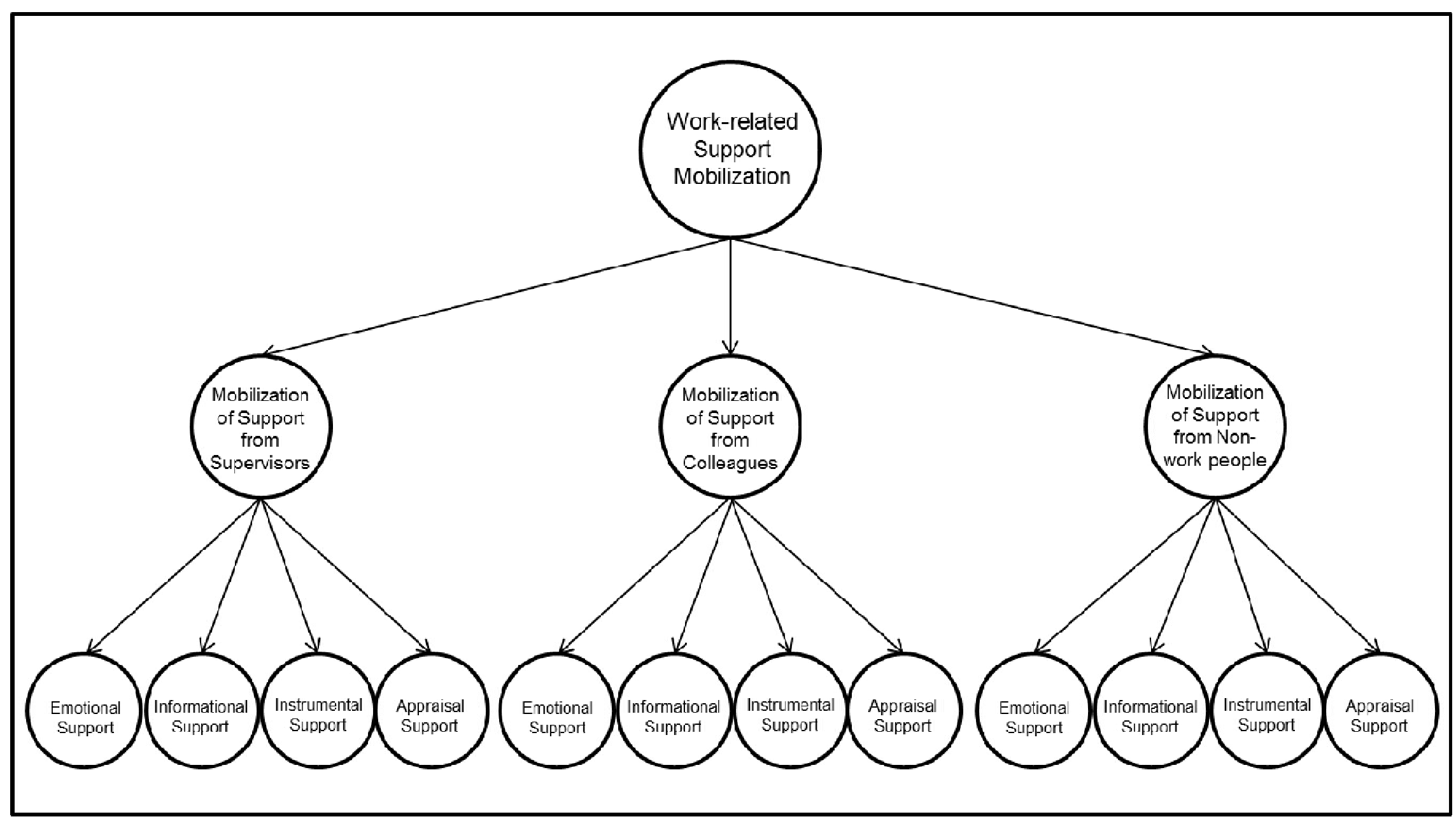

Figure 1. Conceptual model of work-related supportmobilization behaviors 